\title{
THE MiCROSTRUCTURE OF EUTECTIC AU-SN SOLDER BUMPS ON CU/ELECTROLESS NI/AU
}

\author{
H.G. Song ${ }^{1}$, J.P. Ahn ${ }^{2}$ and J.W. Morris, Jr. ${ }^{1}$ \\ ${ }^{1}$ Department of Materials Science and Engineering, University of California at Berkeley \\ and Center for Advanced Materials, Lawrence Berkeley National Laboratory, CA 94720 \\ ${ }^{2}$ National Center for Electron Microscopy, Lawrence Berkeley National Laboratory
}

\begin{abstract}
In this work we studied the initial microstructure and microstructural evolution of eutectic Au-Sn solder bumps on $\mathrm{Cu} / \mathrm{electroless} \mathrm{Ni} / \mathrm{Au}$. The solder bumps were 150-160 $\mu \mathrm{m}$ in diameter and 45-50 $\mu \mathrm{m}$ tall, reflowed on $\mathrm{Cu} / \mathrm{electroless} \mathrm{Ni} / \mathrm{Au}$, and then aged at $200^{\circ} \mathrm{C}$ for up to 365 days. In addition, $\mathrm{Au}-\mathrm{Ni}$-Sn-alloys were made and analyzed to help identify the phases that appear at the interface during aging. The detailed interfacial microstructure was observed using TEM. The results show that the introduction of $\mathrm{Au}$ from the substrate produces large islands of $\zeta$ phase in the bulk microstructure during reflow. Two Au-Ni-Sn compounds are formed at the solder/substrate interface and grow slowly during aging. The maximum solubility of $\mathrm{Ni}$ in the $\zeta$-phase was measured to be about 1 at.\% at $200^{\circ} \mathrm{C}$, while $\mathrm{Ni}$ in the $\delta$-phase is more than 20 at.\%. The electroless Ni layer is made of several sublayers with slightly different compositions and microstructures. There is, in addition, an amorphous interaction layer at the solder/electroless Ni interface.
\end{abstract}

Key words: Au-Sn solder, Electroless Ni/Au metallization, Au-Ni-Sn compounds 


\section{INTRODUCTION}

The microstructure of a solder joint, which governs its mechanical properties, is determined not only by its composition and thermal history, but also by the reactions that occur at the solder/substrate interface.[1] When the joint is fine its composition can be modified significantly by diffusion from the substrate. The microstructures of fine eutectic Au-Sn solder joints on $\mathrm{Cu}$, for example, depend on the amount of $\mathrm{Cu}$ dissolved during the reflow process, [2] and are further modified by the accumulation of $\mathrm{Cu}$ during aging. The dissolution of the substrate may compromise the reliability of the joint through high substrate consumption or void formation, [3] so it is desirable to use substrate metallizations that minimize the interaction between the solder and the substrate.

Electroless $\mathrm{Ni} / \mathrm{Au}$ metallization has become popular in microelectronic packaging since it reduces the process cost while providing a good interfacial diffusion barrier for most Sn-bearing solders.[4-7] However, there has been some concern about the reliability of these joints, given the weak interface between the eutectic $\mathrm{Pb}$-Sn solder and the electroless $\mathrm{Ni} / \mathrm{Au}$ metallization.[8-11] This concern has motivated recent investigations of interfacial reactions [6,7] and failure mechanisms $[12,13]$ in joints that contain electroless Ni layers.

In the case of the eutectic Au-Sn solder, electroless Ni plating is a promising under-bump metallization.[14] However, the Au-Sn-Ni system is complex, and the influence of the electroless Ni layer on the joint and interface microstructure is only partly understood. The present work was undertaken to clarify the microstructure and microstructural evolution of eutectic $\mathrm{Au}-\mathrm{Sn}$ solder (80Au-20Sn by weight) on $\mathrm{Cu} /$ electroless $\mathrm{Ni} / \mathrm{Au}$ substrates, with a particular focus on the solder-substrate interface.

\section{EXPERIMENTAL PROCEDURE}

The samples used in this work were made as 20x20 arrays of solder bumps of eutectic $\mathrm{Au}-\mathrm{Sn}$ solder (80Au-20Sn by weight, 71Au-29Sn by molar content) on Si substrates with $\mathrm{Cu}$ (12 $\mu \mathrm{m}) /$ electroless $\mathrm{Ni}(5 \mu \mathrm{m}) / \mathrm{Au}(0.1 \mu \mathrm{m})$. The bumps were spherical caps $150-160 \mu \mathrm{m}$ in diameter and $45-50 \mu \mathrm{m}$ tall, and the array had a pitch of about $500 \mu \mathrm{m}$ as illustrated in Fig. 1. The bumps

were made with the "bumped" variation of the Z-MAJIC ${ }^{\mathrm{TM}}$ process. [2,15] The reflow includes a 
75 sec. exposure above $280^{\circ} \mathrm{C}$ with a peak temperature of $315^{\circ} \mathrm{C}$, slightly above the $280^{\circ} \mathrm{C}$ melting temperature of eutectic Au-Sn (Fig. 2). [16]

The samples were aged at $200^{\circ} \mathrm{C}$ for up to 365 days. The cross-sectional microstructures of both the as-soldered and aged samples were examined in a scanning electron microscope (SEM) with a back-scattered electron (BSE) detector and an energy-dispersive X-ray (EDX) analyzer. The detailed interfacial microstructure was analyzed by a transmission electron microscope (TEM) with EDX.

Three bulk Au-Ni-Sn alloys were made to study intermetallic phase formation at compositions like those present at the interface. These were made by adding Ni contents of 10 , 20 and 35 mole percent to eutectic Au-Sn. The alloys were vacuum arc melted using 99.999\% pure elements, cast and then annealed at $200^{\circ} \mathrm{C}$ for 20 days.

\section{RESULTS AND DISCUSSION}

\section{A. Microstructure of bulk solder}

The typical cross-sectional microstructure of the as-solidified bump is shown in Fig. 3. The bright constituent in the eutectic microstructure is the $\zeta$-phase (nominally Aus $\mathrm{Sn}$ ) while the darker constituent is the $\delta$-phase (AuSn). In the as-solidified eutectic $\mathrm{Au}-\mathrm{Sn}$ bump on $\mathrm{Cu}, \mathrm{Cu}$ is present throughout the bulk solder due to its high dissolution into the molten solder during reflow.[2] In contrast, Ni was not detected outside the immediate neighborhood of the interface. This result suggests that the dissolution rate of $\mathrm{Ni}$ into molten Au-Sn solder is low as compared to that of $\mathrm{Cu}$. This is consistent with the low solubility of $\mathrm{Ni}$ in the binary Au-Ni and Ni-Sn systems at the reflow temperature. [17]

The bulk of the joint is predominantly $\zeta$-phase $\left(\mathrm{Au}_{5} \mathrm{Sn}\right)$. The large islands of $\zeta$ are due to the thin protective layer of $\mathrm{Au}$ on the initial substrate, which is deposited to ensure wetting by the solder. Once the solder is molten, between $280^{\circ} \mathrm{C}$ and $315^{\circ} \mathrm{C}$, the top Au layer dissolves and slightly increase the overall $\mathrm{Au}$ content of the liquid solder into Au-rich off-eutectic composition (Fig. 2), resulting in the formation of proeutectic $\zeta$-phase during solidification. A similarly prominent $\zeta$-phase is found at the as-solidified interfaces of $\mathrm{Au}-\mathrm{Sn}$ bumps on $\mathrm{Cu}$. However, this is not just the Au-Sn binary $\zeta$-phase observed in the present system, but is rather a $\zeta$-phase with a 
high $\mathrm{Cu}$ solubility $(\zeta(\mathrm{Cu}))$. This phase is formed by the high dissolution rate of $\mathrm{Cu}$ into the liquid solder and the high solubility of $\mathrm{Cu}$ in $\zeta$-phase.[2]

The eutectic lamellae in the Au-Sn solder bumps on Ni are much coarser than those found in as-solidified eutectic Au-Sn bumps on $\mathrm{Cu}$ (Fig. 4) which had the same geometry and thermal history. The reason is unclear, but must also be an effect of the $\mathrm{Cu}$ dissolution into the solder.

An irregular-shaped intermetallic phase was observed at the interface between the solder and the electroless Ni metallization as shown in Fig. 3(b). High magnification BSE imaging was used to clarify the morphology of this phase. The average thickness of this intermetallic phase was about $0.7 \mu \mathrm{m}$. Compositional analysis by EDX shows that it is a Au-Ni-Sn compound of the measured composition (22-25) $\mathrm{Au}(35-38) \mathrm{Ni}(38-41) \mathrm{Sn}$ (in atom percent), which corresponds to the $\mathrm{Ni}_{3} \mathrm{Sn}_{2}$ phase with a high $\mathrm{Au}$ solubility, $(\mathrm{Au}, \mathrm{Ni})_{3} \mathrm{Sn}_{2}$. While no other interfacial phases were noticed in the SEM micrographs, an additional Au-Ni-Sn phase was found by EDX. It forms a layer between the $(\mathrm{Au}, \mathrm{Ni})_{3} \mathrm{Sn}_{2}$ and the Au-Sn binary phases in the bulk solder, and is identified as a $\delta$ phase with $\mathrm{Ni}$, specifically (Au,Ni) Sn, with composition (42-45) $\mathrm{Au}(5-8) \mathrm{Ni}(46-49) \mathrm{Sn}$.

The same binary phases with the solubility of a third element were found in the bulk AuNi-Sn alloys. The results are summarized in Table 1 and compared to those inferred from reported isothermal sections of the ternary phase diagram at room temperature [18] and $400^{\circ} \mathrm{C}$.[19] $\mathrm{Ni}$ is much more soluble in the $\zeta$-phase than in the $\delta$-phase. The maximum solubility of $\mathrm{Ni}$ in $\zeta$ was about 1 at. $\%$ at $200^{\circ} \mathrm{C}$, while the $\delta$-phase dissolved more than 20 at.\% Ni. It follows that $\mathrm{Ni}$ reacts primarily with the $\delta$-phase rather than $\zeta$-phase in solder joints, as is confirmed by compositional analyses of the two phases at the interface of aged solder bumps, reported below.

Figure 5 shows the microstructure of eutectic $\mathrm{Au}-\mathrm{Sn}$ on $\mathrm{Ni}$ after aging at $200^{\circ} \mathrm{C}$. As the joint ages, the eutectic lamellae in the bulk solder coarsen and become globular. As Ni gradually diffuses into the solder, the irregular $(\mathrm{Au}, \mathrm{Ni})_{3} \mathrm{Sn}_{2}$ intermetallic layer at the interface becomes flat and the $\delta$-based (Au,Ni)Sn becomes more distinct (Fig. 5(c)). The measured compositions of the $(\mathrm{Au}, \mathrm{Ni})_{3} \mathrm{Sn}_{2}$ and $(\mathrm{Au}, \mathrm{Ni}) \mathrm{Sn}$ layers in Fig. 5(c) are (22-26) $\mathrm{Au}(34-38) \mathrm{Ni}(40-41) \mathrm{Sn}$ and (3235) $\mathrm{Au}(21-24) \mathrm{Ni}(44-46) \mathrm{Sn}$, respectively. The composition varies across each layer with the $\mathrm{Au}$ content slightly higher on the solder side and $\mathrm{Ni}$ content higher toward the substrate. The thickness of the total interfacial intermetallic layer is plotted as a function of time in Fig. 6. The layer thickens with $\mathrm{t}^{1 / 2}$, as is normal for diffusion-controlled growth. The growth rate of the 
interfacial layer in this system is only about half the growth rate of the interfacial layers in eutectic Au-Sn bumps on $\mathrm{Cu}$. [2]

The phase distribution at the interface changes qualitatively on aging. The $\delta$-phase adjacent to the interfacial layer is gradually replaced by the $\zeta$-phase, which eventually covers the interfacial layer as shown in Fig. 5(b). This microstructural change results from the Ni solubility difference in the $\zeta$ - and $\delta$-phases. Since Ni solubility in the $\zeta$-phase is below 1 at.\%, Ni is not incorporated into the $\zeta$-phase. Instead, the $\zeta$ near the interface acts as a source of Au and Sn for the interfacial phases which are relatively rich in $\mathrm{Sn}$. As the interfacial layers grow, Au is obtained by consuming the $\zeta$-phase. On the solder side, the $\delta$-phase, which has a high $\mathrm{Ni}$ solubility, incorporates $\mathrm{Ni}$ and releases $\mathrm{Au}$ as it converts into the (Au,Ni)Sn phase. The Au that is released causes lateral growth of the $\zeta$-phase and increases its volume fraction at the interface. The islands of $\zeta$-phases spread along the interface and contact to form a continuous layer. Once the $\zeta$-phase covers the interfacial layer, it acts as a diffusion barrier that inhibits the flow of $\mathrm{Ni}$ to the bulk solder. In fact, the Ni in the bulk solder is small even after aging for 365 days at $200^{\circ} \mathrm{C}$.

\section{B. Detailed interface microstructure}

The typical electroless Ni plating used in electronic packaging involves phosphorus (P). The $\mathrm{P}$ content and the thermal history determine the structure and properties of the electroless $\mathrm{Ni}$ layer. [20-21] In general, as-plated electroless Ni(Ni-P) layer is amorphous at high P contents (P greater than about 10 at.\%) and tends to crystallize on annealing. There are no significant compositional changes during crystallization. [21]

The $\mathrm{P}$ content of the electroless Ni layer used in this work was measured to be about 12 at\% in the very fine grain region near the $\mathrm{Cu}$ substrate. Figure 7 is a cross-sectional TEM micrograph of the interface between the eutectic Au-Sn solder and the electroless $\mathrm{Ni}$ in the assolidified bump. Different regions of the Ni layer differ in grain size, but all regions are crystalline except for a thin layer immediately beneath the $(\mathrm{Au}, \mathrm{Ni})_{3} \mathrm{Sn}_{2}$ compound. This suggests that the asplated amorphous electroless $\mathrm{Ni}$ in this system crystallized during the reflow process.

The microstructure of the $\mathrm{Ni}$ layer varies with distance beneath the $(\mathrm{Ni}, \mathrm{Au})_{3} \mathrm{Sn}_{2}$ intermetallic at the interface. The sequence of microstructures begins with a thin amorphous reaction layer $(0.16 \sim 0.18 \mu \mathrm{m}$ thick), followed by a fine-grained P-rich region $(0.15 \sim 0.2 \mu \mathrm{m})$, a relatively coarse grained Ni-P region within which the grain size gradually decreases into a fine- 
grained $\mathrm{Ni}-\mathrm{P}(\sim 1.28 \mu \mathrm{m})$, and a uniformly fine-grained $\mathrm{Ni}-\mathrm{P}$ that borders the $\mathrm{Cu}$ substrate. The interfacial reaction for the formation of the $(\mathrm{Ni}, \mathrm{Au})_{3} \mathrm{Sn}_{2}$ intermetallic compounds involves either $\mathrm{Ni}$ diffusion towards the solder side or P diffusion backwards in the electroless Ni layer, which results in the compositional variation of the Ni-P layer near the interface. Considering the fact that the grain size of the electroless Ni-P is related to P content, [20] it appears that about onethird of the electroless $\mathrm{Ni}$ layer participated in the interfacial reaction during the reflow process. We discuss these distinct microstructures in turn.

The interlayer between the interfacial compound and $\mathrm{Ni}_{3} \mathrm{P}$ has a relatively smooth interface with the $(\mathrm{Ni}, \mathrm{Au})_{3} \mathrm{Sn}_{2}$ compound, but an indistinct interface with the lower $\mathrm{Ni}_{3} \mathrm{P}$ layer. All of the four chemical species in the system are involved in this layer; its overall composition is (7-10) $\mathrm{Au}(60-65) \mathrm{Ni}(13-20) \mathrm{Sn}(9-13) \mathrm{P}$. A selective-area diffraction pattern (SADP) of this layer (Fig. 7) shows diffuse ring patterns with weak spots of $\mathrm{Ni}_{3} \mathrm{P}$, suggesting that this layer has an amorphous character with some fine crystalline $\mathrm{Ni}_{3} \mathrm{P}$. While the formation of this amorphous reaction layer is not well understood, it may be partially attributed to the solid-state amorphization found in metal/metal and metal/Si systems.[22,23] The presence of Au may contribute to the formation of this interlayer, since no amorphous layer was observed at the interface between eutectic Pb-Sn and electroless Ni.[6,7] Since an amorphous thin layer is metastable, it is expected that the layer found here will transform into stable crystalline phases, $(\mathrm{Ni}, \mathrm{Au})_{3} \mathrm{Sn}_{2}$ and $\mathrm{Ni}_{3} \mathrm{P}$, during aging.

The material immediately beneath the amorphous layer, is a P-rich region with the composition (22-23)P and with a grain size of about 20nm. SADP analysis shows that this region is a mixture of pure $\mathrm{Ni}$ and the $\mathrm{Ni}_{3} \mathrm{P}$ phase. This microstructure apparently forms by crystallization during reflow as described above.

The coarse-grained layer beneath this, which was not observed in the $\mathrm{Pb}-\mathrm{Sn}$ system on Ni-P, [6,7] has an average grain size of about $60 \mathrm{~nm}$ and a $\mathrm{P}$ content of $5 \sim 8$ at $\%$. The grain size gradually decreases across this layer towards the $\mathrm{Cu}$ side with an associated increase in the $\mathrm{P}$ content. The innermost Ni-P layer has a uniform grain size and composition.

A TEM study on the evolution of the interfacial microstructure is in progress.

\section{SUMMARY}

The typical microstructure of a eutectic Au-Sn solder bump on a $\mathrm{Cu} /$ electroless $\mathrm{Ni} / \mathrm{Au}$ substrate contains large proeutectic $\zeta$-phases due to the dissolution of the Au protective layer 
during soldering together with a $\zeta-\delta$ lamellar eutectic constituent. At the interface, two different $\mathrm{Au}-\mathrm{Ni}$-Sn compounds form in an interfacial intermetallic layer that thickens at only about half the rate $\mathrm{Cu}-\mathrm{Au}$ compounds at the interface of eutectic $\mathrm{Au}-\mathrm{Sn} / \mathrm{Cu}$.

The maximum solubility of $\mathrm{Ni}$ in the $\zeta$-phase is $\sim 1$ at. $\%$ at $200^{\circ} \mathrm{C}$, while $\mathrm{Ni}$ solubility in the $\delta$-phase is more than 20 at.\%. It follows that Ni reacts primarily with the $\delta$-phase rather than the $\zeta$-phase

The electroless Ni layer is made of several sublayers with slightly different compositions and microstructures. There is, in addition, an amorphous interaction layer at the solder/electroless $\mathrm{Ni}$ interface.

\section{ACKNOWLEDGMENTS}

This research was supported by the Director, Office of Energy Research, Office of Basic Sciences, U. S. Department of Energy, under Contract No. DE-AC03-76SF00098.

\section{REFERENCES}

1. J.W. Morris, Jr. and H.L. Reynolds, EEP-Vol.19-2, Adv. Electr. Pkg. 2, 1529 (1997)

2. H.G. Song, J.W. Morris, Jr. and M.T. McCormack, J. Electr. Mater. 29, 1038 (2000)

3. E. Zakel and H. Reichl, IEEE Trans. Comp. Hybrids, Manuf. Technol. 16, 323 (1993)

4. C.Y Lee and K.L. Lin, Thin Solid Films 249, 201 (1994)

5. E. Zakel and T. Teutsch, Proc. 22nd IEEE/CPMT Int. Electr. Manuf. Technol. Symp. (New York, NY: IEEE, 1998), p. 55

6. J.W. Jang, P.G. Kim, K.N. Tu, D.R. Frear and P. Thompson, J. Appl. Phys. 85, 8456 (1999)

7. P.L. Liu, Z. Xu and J.K. Shang, Metall. Mater. Trans. A 31A, 2857 (2000)

8. E. Bradley and K. Banerji, IEEE Trans. Comp. Pkg., Manuf. Technol. Part B, 19, 320 (1996)

9. Z. Mei, M. Kaufmann, A. Eslambolchi and P. Johnson, Proc. 48th Electr. Comp. Technol. Conf. (New York, NY: IEEE, 1998), p. 952 
10. R.J. Coyle, A. Holliday, P. Mescher, P.P. Solan, S.A. Gahr, H.A.Cyker, J.K. Dorey and T.I. Ejim, 24nd IEEE/CPMT Int. Electr. Manuf. Technol. Symp. (Piscataway, NJ: IEEE, 1999), p. 23

11. Z. Mei, P. Johnson,M. Kaufmann and A. Eslambolchi, Proc. 49th Electr. Comp. Technol. Conf. (Piscataway, NJ: IEEE, 1999), p. 125

12. J.W. Jang, C.Y. Liu, P.G. Kim, K.N. Tu, A.K. Mal and D.R. Frear, J. Mater. Res. 15, 1679 (2000)

13. P.L. Liu and J.K. Shang, Metall. Mater. Trans. A 31A, 2867 (2000)

14. S. Anhock, A. Ostmann, H. Oppermann, R. Aschenbrenner, and H. Reichl, Proc. Int. Symp. Adv. Pkg. Mater. (Reston, VA: IMAPS, 1999), p. 256

15. M.T. McCormack, H. Jiang, S.I. Beilin, B. Chou, and M. Peters, EEP-Vol.26-2, Adv. Electr. Pkg. 2, 1807 (1999)

16. G.S. Matijasevic, C.C. Lee, and C.Y. Wang, Thin Solid Films 223, 276 (1993)

17. T.B. Massalski, H, Okamoto, P.R. Subramanian and L. Kacprzak, Binary alloy phase diagrams, 2nd ed. (Materials Parks, OH: ASM int., 1990)

18. S. Anhock, H. Oppermann, C. Kallmayer, R. Aschenbrenner, L. Thomas, H. Reichl, Proc. 22th IEEE/CPMT Int. Electr. Manuf. Technol. Symp. (New York, NY: IEEE, 1998), p. 156

19. A. Neumann, A. Kjekshus and E. Rest, J. Solid State Chem. 123, 203 (1996)

20. R. M. Allen and B. VanderSande, Scr. Metall. 16, 1161 (1982)

21. H. Li, H. Chen, S. Dong, J. Yang and J. Deng, Appl. Surf. Sci. 125, 115 (1998)

22. W. Reidel, Electroless Nickel Plating (Metals Park, OH: ASM Int., 1991), p 79

23. Q. Zhang, W.S. Lai, G.W. Yang and B.X. Liu, J. Phys.: Condens. Matter 12, 6991 (2000)

24. L.J. Chen, Mater. Sci. Eng. R29, 115 (2000)

\section{FIGURE AND TABLE CAPTIONS}

Figure 1. Schematic diagram of the sample geometry.

Figure 2. Au-AuSn binary phase diagram.[16]

Figure 3. Cross-sectional micrographs of as-solidified solder bump on $\mathrm{Cu} / \mathrm{electroless} \mathrm{Ni} / \mathrm{Au}$.

(a) SEM image at low magnification (b) BSE image at high magnification 
Figure 4. Cross-sectional SEM image of as-solidified $\mathrm{Au}-\mathrm{Sn}$ solder bump on $\mathrm{Cu}$. $(\zeta(\mathrm{Cu})$ denotes the binary $\zeta$ phase with a high $\mathrm{Cu}$ solubility.)

Figure 5. Cross-sectional micrographs of solder joints aged at $200^{\circ} \mathrm{C}$ (a) for 50 days (SEM image), (b) for 365 days (SEM image) and (c) for 365 days. (BSE image at high magnification)

Figure 6. Thickness of total Au-Ni-Sn interfacial intermetallic layers with the square root of aging time at $200^{\circ} \mathrm{C}$.

Figure 7. TEM image of the interface between the solder and the electroless $\mathrm{Ni}$ in the as-solidified bump.

Table 1. Comparison of constituent phases in different isothermal sections. 


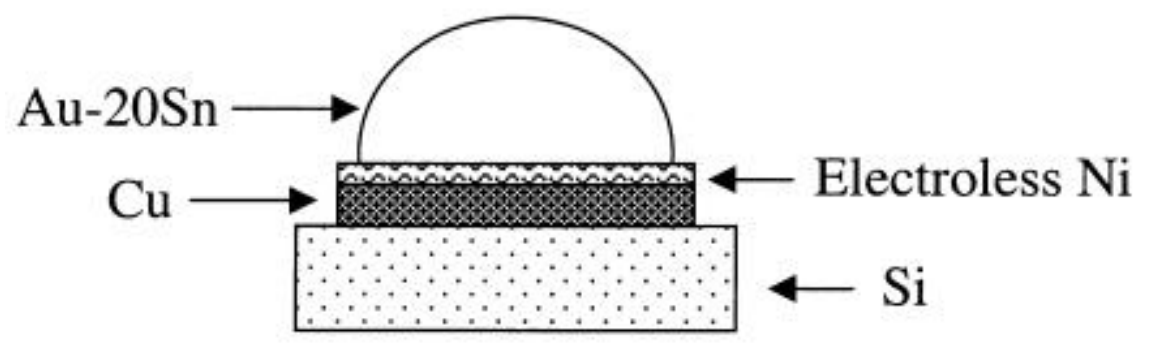

Figure 1. Schematic diagram of the sample geometry.

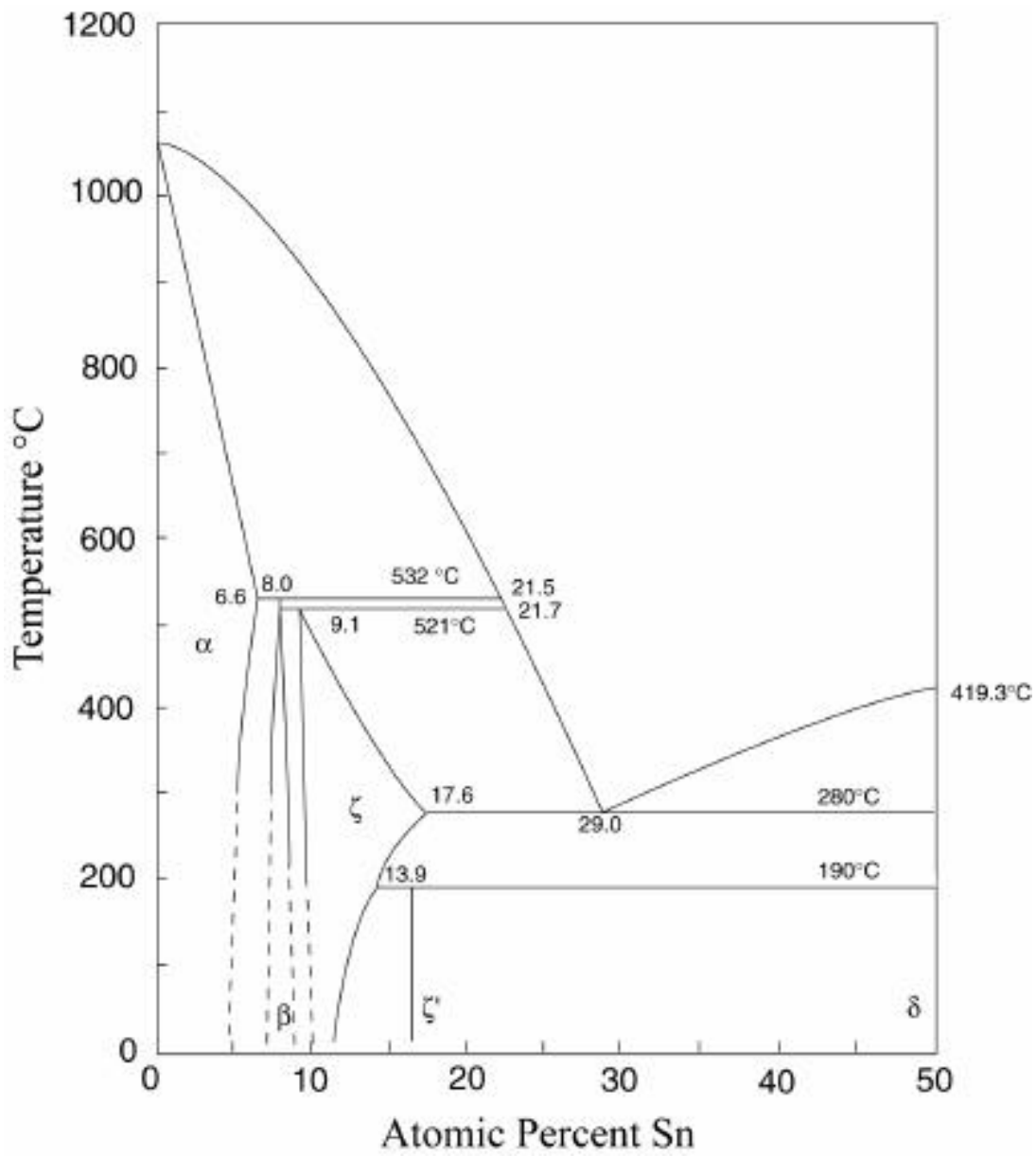

Figure 2. Au-AuSn binary phase diagram.[16] 
(a)

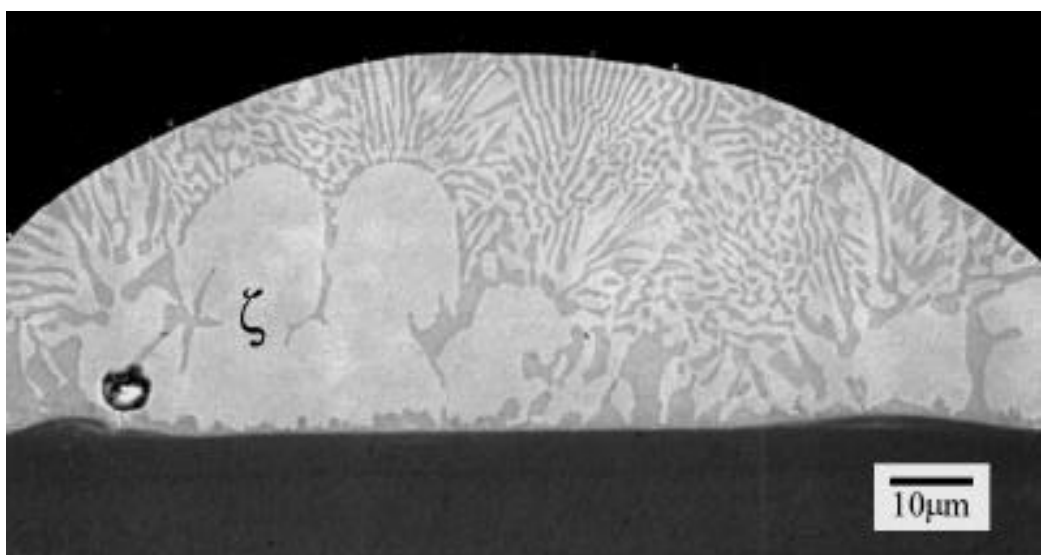

(b)

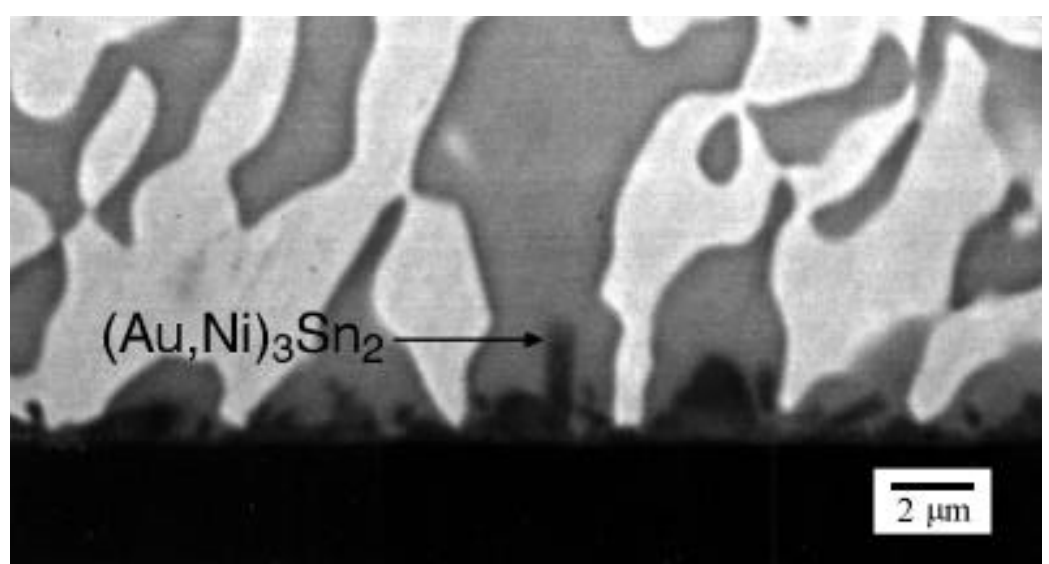

Figure 3. Cross-sectional micrographs of as-solidified solder bump on $\mathrm{Cu}$ /electroless $\mathrm{Ni} / \mathrm{Au}$

(a) SEM image at low magnification

(b) BSE image at high magnification

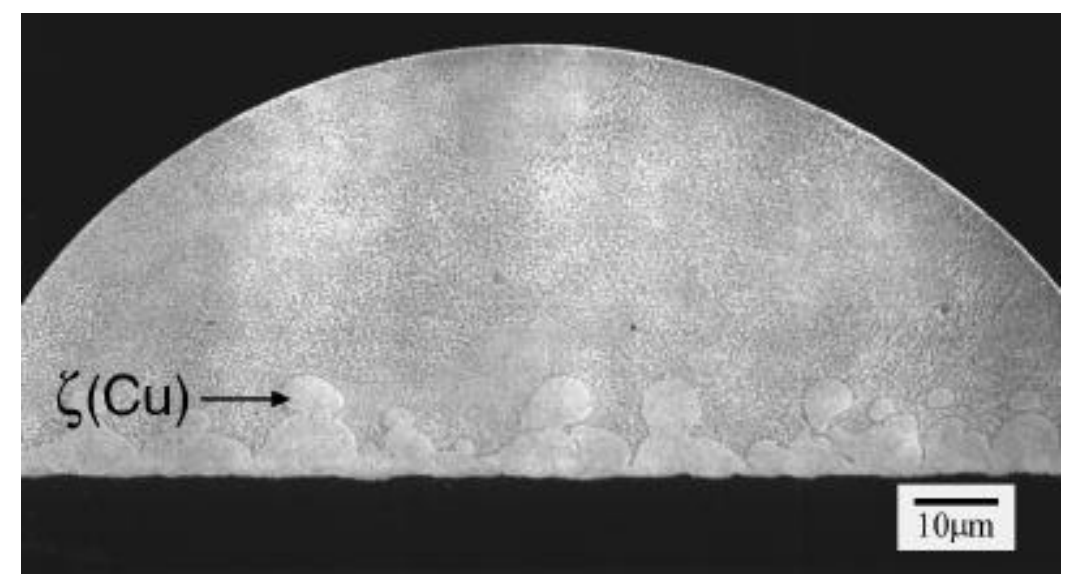

Figure 4. Cross-sectional SEM image of as-solidified AuSn solder bump on $\mathrm{Cu}$. ( $\zeta(\mathrm{Cu})$ denotes the binary $\zeta$ phase with a high $\mathrm{Cu}$ solubility.) 
(a)

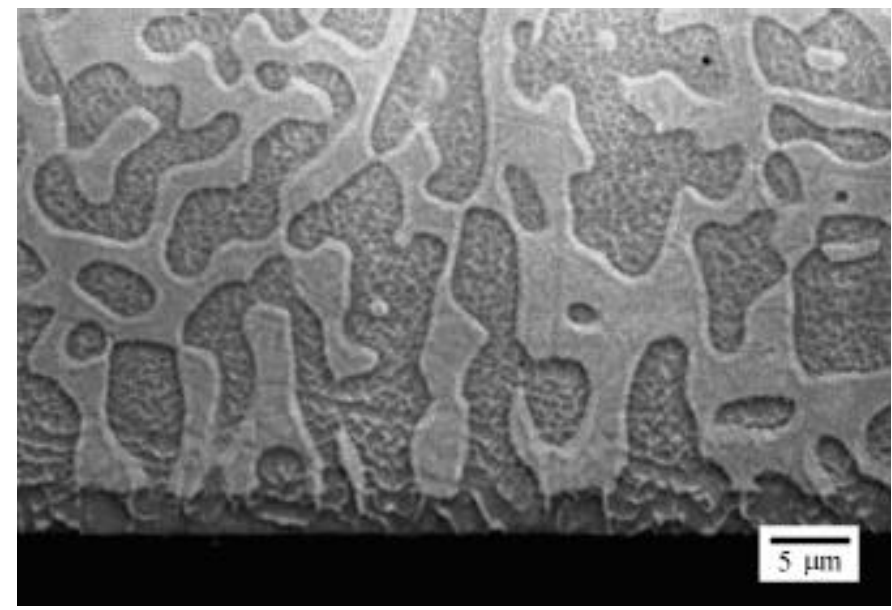

(b)
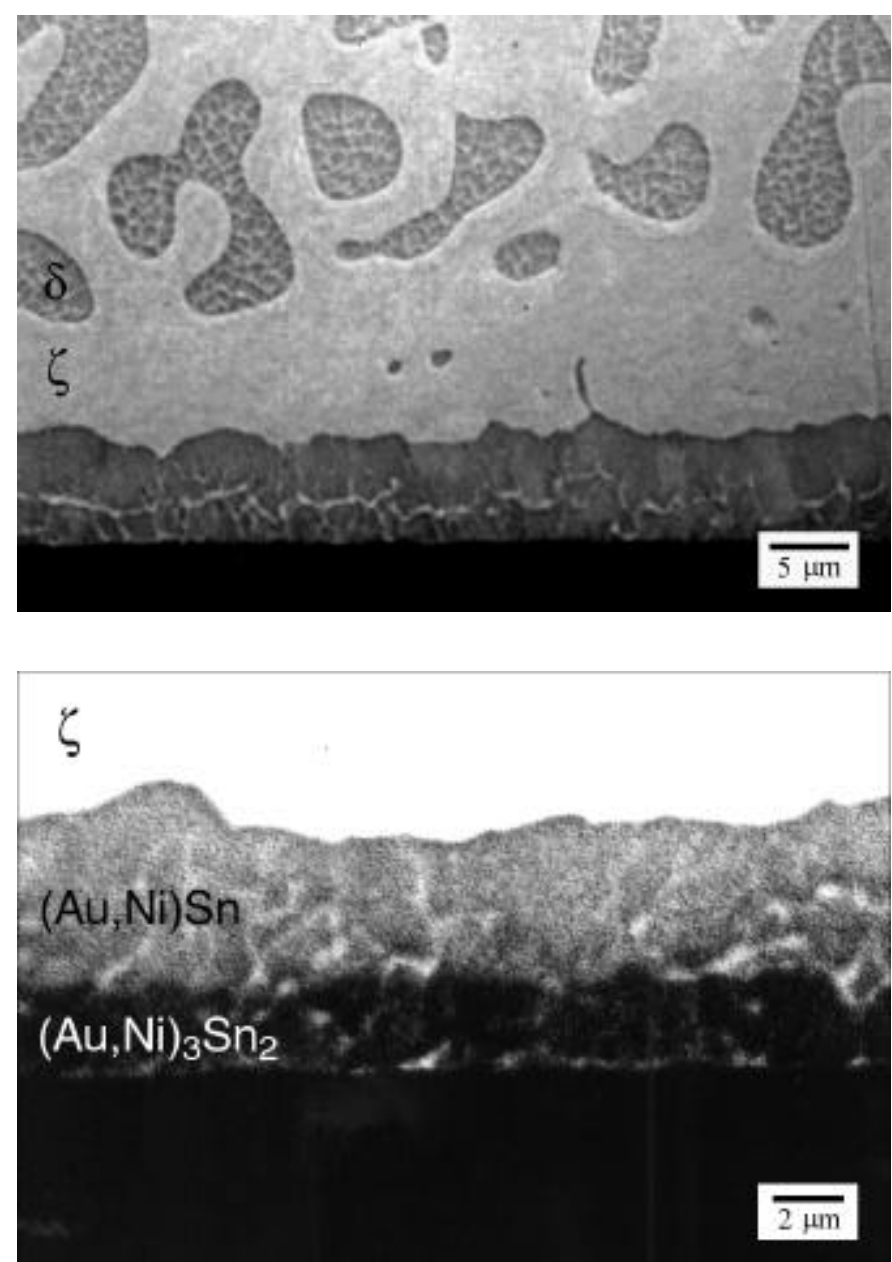

Figure 5. Cross-sectional micrographs of solder joints aged at $200^{\circ} \mathrm{C}$ (a) for 50 days (SEM image), (b) for 365 days (SEM image) and (c) for 365 days. (BSE image at high magnification) 


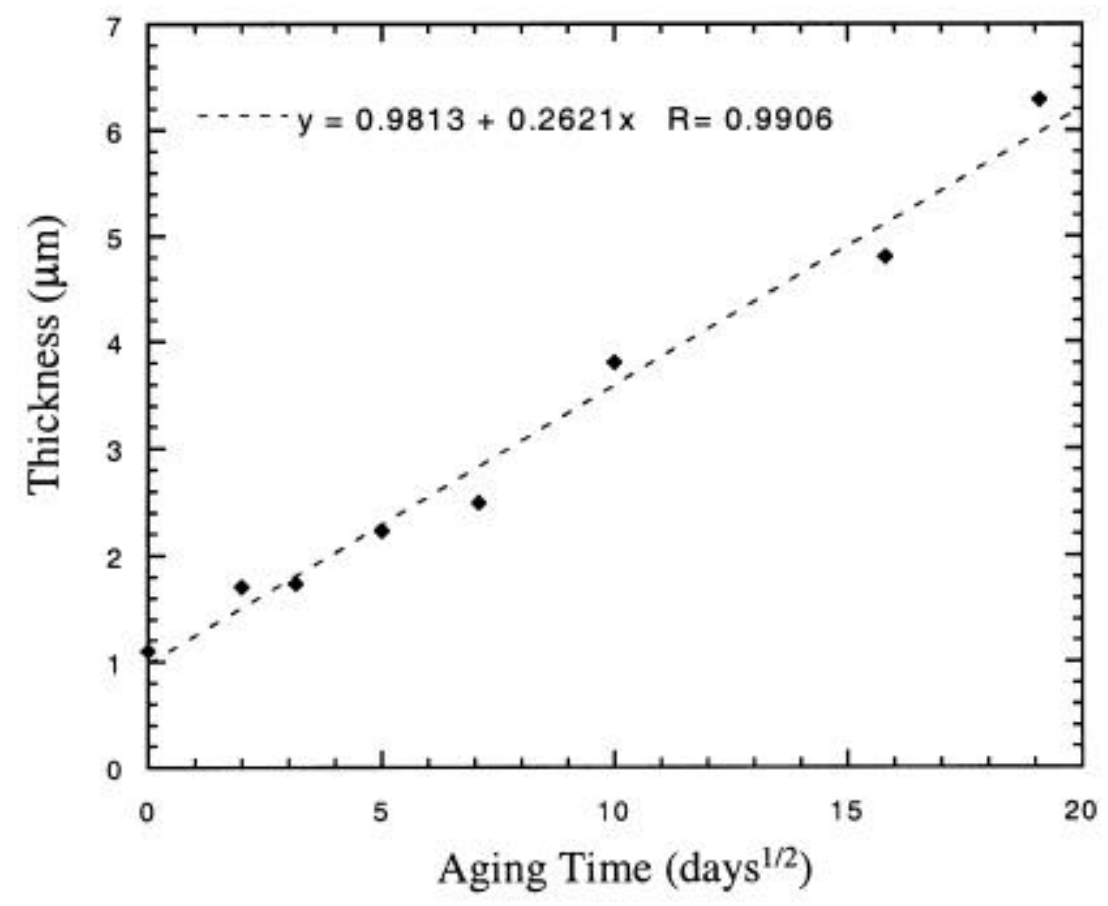

Figure 6. Thickness of total Au-Ni-Sn interfacial intermetallic layers with the square root of aging time at $200^{\circ} \mathrm{C}$.

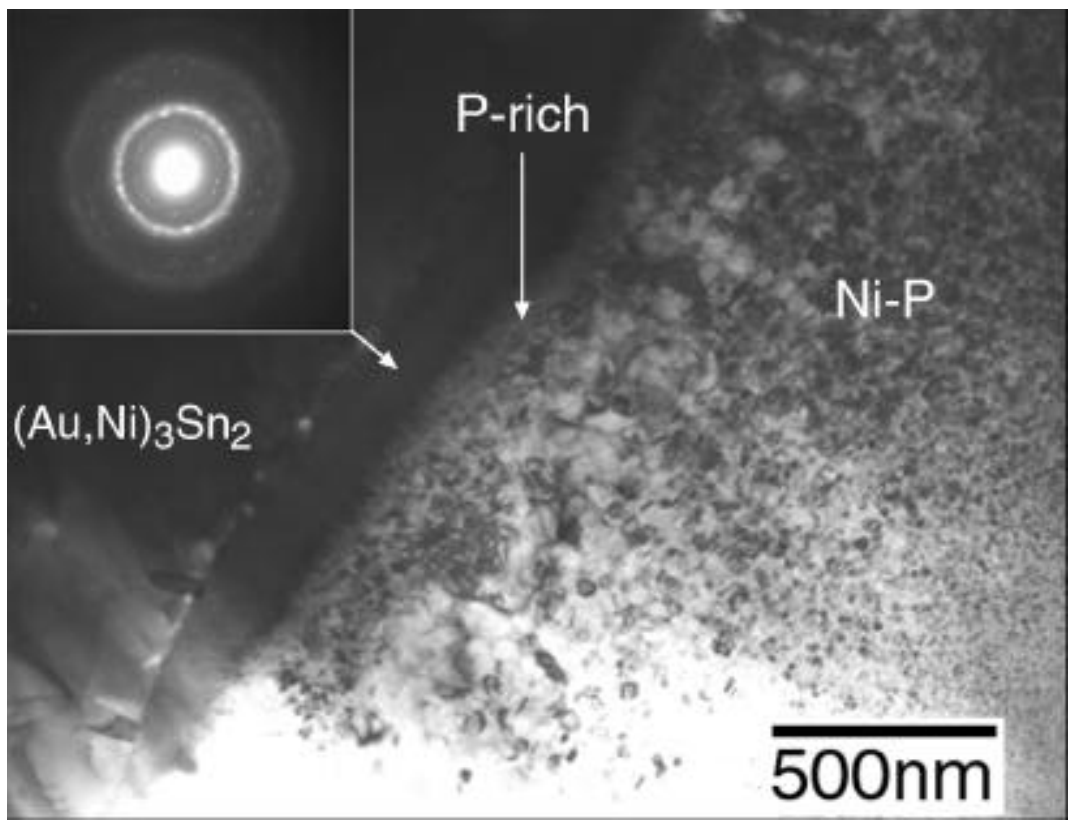

Figure 7. TEM image of the interface between the solder and the electroless $\mathrm{Ni}$ in the as-solidified bump 
Table 1. Comparison of constituent phases in different isothermal sections.

\begin{tabular}{|c|c|c|c|}
\hline & $\begin{array}{c}\text { Eutectic } \mathrm{AuSn} \\
\text { with } 10 \text { at. } \% \mathrm{Ni}\end{array}$ & $\begin{array}{c}\text { Eutectic } \mathrm{AuSn} \\
\text { with } 20 \text { at. } \% \mathrm{Ni}\end{array}$ & $\begin{array}{c}\text { Eutectic AuSn } \\
\text { with } 35 \text { at. } \% \mathrm{Ni}\end{array}$ \\
\hline Room Temperature & $\zeta+\delta(\mathrm{Ni})+\mathrm{Ni}_{3} \mathrm{Sn}_{2}(\mathrm{Au})$ & $\begin{array}{c}\mathrm{Au}(\mathrm{Ni}, \mathrm{Sn}) \\
+\zeta(\mathrm{Ni})+\mathrm{Ni}_{3} \mathrm{Sn}_{2}(\mathrm{Au})\end{array}$ & $\mathrm{N} / \mathrm{A}$ \\
\hline $200^{\circ} \mathrm{C}$ & $\zeta+\delta(\mathrm{Ni})+\mathrm{Ni}_{3} \mathrm{Sn}_{2}(\mathrm{Au})$ & $\zeta(\mathrm{Ni})+\mathrm{Ni}_{3} \mathrm{Sn}_{2}(\mathrm{Au})$ & $\begin{array}{c}\mathrm{Au}(\mathrm{Ni}, \mathrm{Sn})+ \\
\mathrm{Ni}_{3} \mathrm{Sn}(\mathrm{Au})+\mathrm{Ni}_{3} \mathrm{Sn}_{2}(\mathrm{Au})\end{array}$ \\
\hline $400^{\circ} \mathrm{C}$ & $\zeta+\mathrm{L}+\mathrm{Ni}_{3} \mathrm{Sn}_{2}(\mathrm{Au})$ & $\zeta(\mathrm{Ni})+\mathrm{Ni}_{3} \mathrm{Sn}_{2}(\mathrm{Au})$ & $\begin{array}{c}\mathrm{Au}\left(\mathrm{Ni}, \mathrm{Sn}_{2}\right)+ \\
\mathrm{Ni}_{3} \mathrm{Sn}(\mathrm{Au})+\mathrm{Ni}_{3} \mathrm{Sn}_{2}(\mathrm{Au})\end{array}$ \\
\hline
\end{tabular}

